\title{
VARIABILITY OF BIOMASS BURNING AEROSOLS LAYERS AND NEAR GROUND
}

\author{
Jeni Vasilescu $^{1 *}$, Livio Belegante ${ }^{1}$, Luminita Marmureanu${ }^{1}$, Flori Toanca ${ }^{1,2}$ \\ ${ }^{I}$ National Institute of R\&D for Optoelectronics, Magurele, 077125, Romania, *Email: jeni@inoe.ro \\ ${ }^{2}$ University of Bucharest, Faculty of Physics, P.O.BOX MG-11, Magurele - Bucharest,
}

077125, Romania

\begin{abstract}
The aim of this study is to characterize aerosols from both chemical and optical point of view and to explore the conditions to sense the same particles in elevated layers and at the ground. Three days of continuous measurements using a multi-wavelength depolarization lidar(RALI) and a C-ToF-AMS aerosol mass spectrometer are analyzed. The presence of smoke particles was assessed in low level layers from RALI measurements. Chemical composition of submicronic volatile/semi-volatile aerosols at ground level was monitored by the CTOF AMS
\end{abstract}

Several episodes of biomass burning aerosols have been identified by both techniques due to the presence of specific markers $(f 60$, linear particle depolarization ratio, Ängström exponent).

\section{INTRODUCTION}

Aerosol size distributions, chemical composition, optical and microphysical retrievals provide essential information regarding local and long range transported aerosols [1]. Frequently, the atmospheric layers contain combination of different aerosol types picked up during transport, which can be dry deposited on the ground or remain suspended at higher altitudes [2].

Numerous studies are discussing independently the chemical and physical properties of aerosols, as well as their origin and local component [3][4][5]. The lidar observations and aerosol mass spectrometer ground based measurements can be combined in order to assess the contribution of long range transported aerosols at ground level and to retrieve their chemical and optical properties, including the level of oxidation, dimension, shape, lidar ratio, Angstrom exponents, linear particle depolarization ratio etc. [6].

Multi-wavelength Raman lidars are suitable to track the levels of aerosols layers, their thickness and variability in time, as well as type dependent aerosols properties. Linear particle depolarization ratio can be used to differentiate between highand low-depolarizing particles, to assess a possible dust intrusion or particles from wild fires [2]. The variability of smoke particles properties and vertical distribution have been intensively studied all over the world, discrepancies being observed even though sometimes the studies focused on the same origin and loads of aerosols [1][3][5]. Several studies already demonstrated that during the aging process Ängström exponent of the biomass burning aerosols decreases from around 2 down to 1 , highlighting an increase of the particle size [1].

Organic ions loadings and proportions of smoke markers can be used to demonstrate the presence of biomass burning aerosols at ground level [7][6]. Besides organic component these aerosols contain high proportions of sulfate, nitrate and small amounts of ammonium and chloride fractions. Generally m/z 43, 44, 60 and 73 ions are used to characterize both the biomass burning presence and their aging process. The mechanism of aging process of biomass burning aerosols are still poorly described, but gives important insights of the chemical and physical evolution of organic aerosols. Depending on the level of oxidation the secondary aerosols, the oxygenated organic aerosols (OOA), could be separated into lowvolatility OOA (LV-OOA - the more oxidized component) and semi-volatile OOA (SV-OOA). In this paper several cases of biomass burning 
aerosols are identified and analyzed using lidar and mass spectrometry techniques.

\section{METHODOLOGY}

Collocated instruments have been used to sense biomass burning aerosols at Magurele site (44.35 N, 26.03 E) near Bucharest, Romania. Three days of continuous measurements of the multiwavelength depolarization lidar [8] and C-ToF aerosol mass spectrometer have been evaluated. Frequently during summer the Romanian atmosphere has influences of biomass-burning and dust long range transported aerosols as a result of complex dynamics of the air masses [2].

A Compact Time of Flight aerosol mass spectrometer model (C-ToF AMS), based on the Aerodyne quadrupole mass spectrometer measured the chemical composition and size resolved mass concentration of aerosols [7]. The submicronic aerosols were sampled with a $2.5 \mu \mathrm{m}$ cyclone, aerodynamically focused and vaporized at $600^{\circ} \mathrm{C}$. Several papers describe the operation principal and application of this instrument to ambient aerosol sampling [9][7]. The mass spectrum and time of flight modes are used to study both chemical composition on five important fractions and chemical resolved size distribution. The average concentration of organics, sulfate, nitrate, ammonium, chloride fractions are available with high time resolution, giving the possibility to sense loadings variations. The most important ions used to assess the fragments are: organics (43, 44, 55 and 57), sulphate $(48,64)$, ammonium $(15,16)$ and nitrate $(30,46)[9]$.

The multi-wavelength Raman lidar system is frequently used in the frame of EARLINET (European Aerosol Lidar Network) for tropospheric measurements [2]. The lidar signal, at $3.75 \mathrm{~m}$ vertical resolution is collected at 1064 , 532p, 532s, 355, 607, 387 and $408 \mathrm{~nm}$, most of the channels having both analog and photon counting detection. The backscatter coefficients $(1064,532,355 \mathrm{~nm})$, extinction coefficients (532, $355 \mathrm{~nm})$ and linear particle depolarization ratio $(532 \mathrm{~nm})$ of aerosols between 0.8 and $10 \mathrm{~km}$ altitude are usually used to assess the aerosols presence and their optical properties [6].
The data analysis for the three days continuous measurements started with detection of aerosol layers near ground and those with low linear particle depolarization ratios. Hysplit (Hybrid Single Particle Lagrangian Integrated Trajectory) model have been used to check the possible regional source of the aerosols, while the MODIS (Moderate Resolution Imaging Spectroradiometer) global fire maps to assess a possible smoke particles presence. From C-ToF AMS the $\mathrm{m} / \mathrm{z} 43,44,60$ and 73 ions evolutions were considered to identify the biomass burning aerosols presence at ground and their oxidation level.

\section{RESULTS}

During the intensive lidar measurements the layers were generally present above $2 \mathrm{~km}$ and below $6 \mathrm{~km}$ altitude, but the descent of air masses from the free troposphere to the ground was favorable. The lofted layers reached the ground after downward mixing in the planetary boundary layer for several hours during the continuous lidar measurement. Three predominant layers near ground were typically sensed (altitude lower than $1.5 \mathrm{~km}$, between $1.5-2.5 \mathrm{~km}$ and above $2.5 \mathrm{~km}$ ). The tendency of the first two aerosols lidar layers to mix with the planetary boundary layer can be observed in the time series of the average height of the layers (Figure 1).

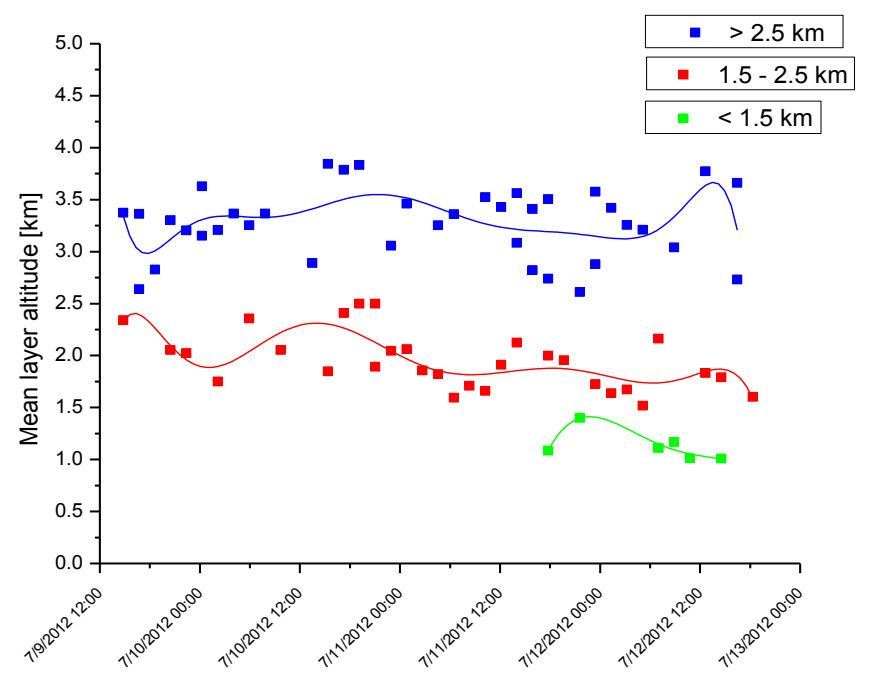

Figure 1 Average lidar layers variation (green-lower layer, near planetary boundary layer, altitude lower than 1.5KM; red - second layer, 1.5-2.5 km; bluethird layer, altitude higher than $2.5 \mathrm{~km}$ ) 
More spherical particle were observed in higher layers, while particles with increased depolarization values were evidenced for lower layers above measurement site during the investigated period (Figure 2). The higher linear depolarization ratio $(\sim 9 \%)$ could corresponds to smoke mixed with urban aerosols, while smaller depolarization values $(\sim 3 \%)$ for lofted layers to smoke or industrial type. On $11^{\text {th }}$ of July 2012 conversion from small to higher values of depolarization, from higher to lower layers can be seen. This could be a case of downward mixing into the planetary boundary layer.

The Ängström backscatter-related coefficient values are higher than 1.2 for more than $50 \%$ of the three days data, which also indicate the presence of small particles; usually the presence of smoke. Two periods of Ängström backscatterrelated coefficient values higher than 1.2 were noticed: in the afternoon of $10^{\text {th }}$ and from $11^{\text {th }}$ to $13^{\text {th }}$ of July.

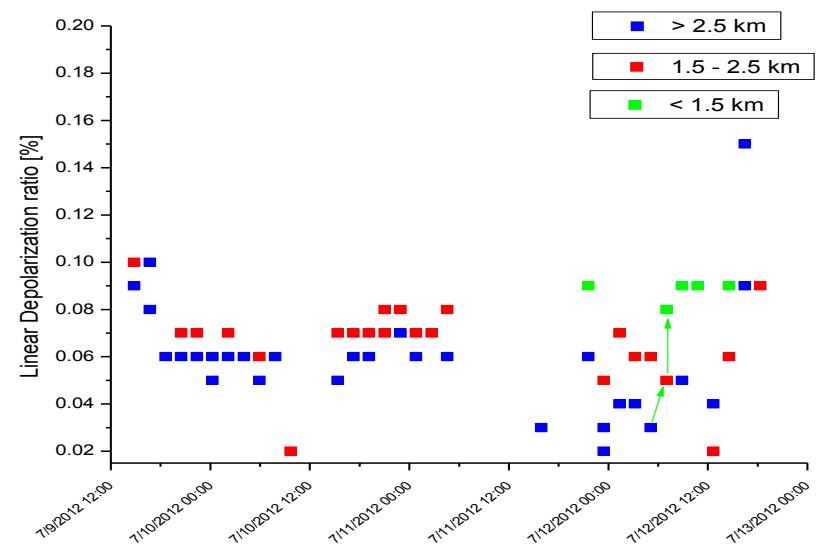

Figure 2 Average linear particle depolarization at $532 \mathrm{~nm}$ of the three Lidar layers, arrows indicate the conversion from low to higher depolarizing particles

Organics, sulfate, ammonium and nitrate fractions presented high loads during the three days continuous measurements. The organics species represented more than $50 \%$ from the total mass of the non-refractory submicronic aerosols (Figure 3). Higher concentrations were evidenced during night time due to the low planetary boundary layer height.

The $\mathrm{m} / \mathrm{z} 60$ fragment represent a marker for "levoglucosan like" species - based organics, indicating the presence of biomass burning aerosols. Its concentration varied same as $\mathrm{m} / \mathrm{z} 73$, high values of $f 60$ (ratio of $\mathrm{m} / \mathrm{z} 60$ to total organic fragment loadings) and $f 73$ being retrieved for the entire campaign. The $f 60$ is present for all AMS measurements, a threshold value indicates the biomass burning influence or non-biomass burning sources. During our intensive measurements period the $f 60$ exceeded very often the background level (0.003) found by Cubison paper [4], indicating the presence of biomass burning aerosols. Doubled than the background level $f 60$ values were noticed for between $11^{\text {th }}$ and $13^{\text {th }}$ of July, when Hysplit back-trajectories showed air masses travelling from the West of Europe [10] and Balkans where MODIS fire map revealed a high density of forest fires.

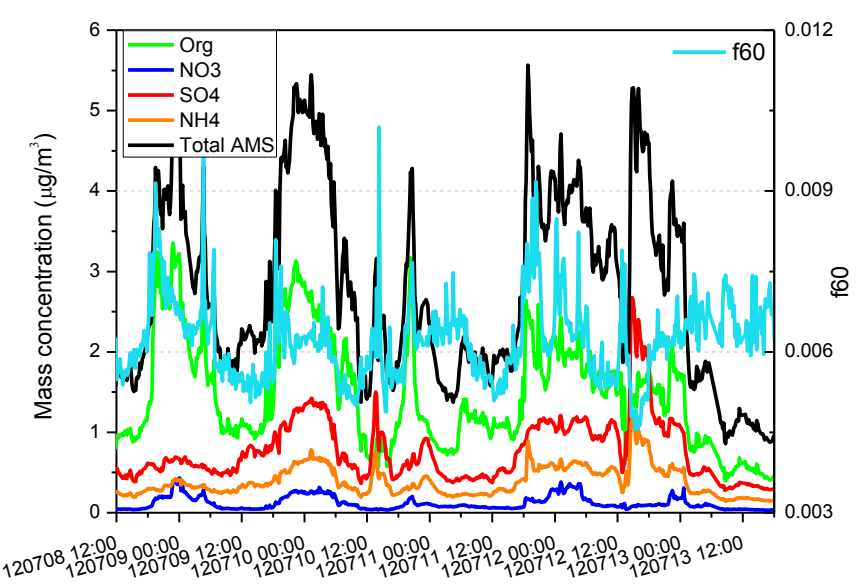

Figure 3 PMI chemical fractions and total concentration time series as measured by CTOF AMS

The $f 44$ versus $f 60$ plot suggested the increasing oxidation state of the organic aerosols (Figure 4). The regional LV-OOA represents the more oxidized component, higher $f 44$ (ratio of $\mathrm{m} / \mathrm{z} 44$ to total organic fragment loadings) values is present for $70 \%$ of the data. The less oxidized organic aerosols component (SV-OOA), characterized by lower $f 44$, is highlighted mostly for $9^{\text {th }}-10^{\text {th }}$ of July and few hours on the $12^{\text {th }}$. The aging process of aerosols can be also identified using the Cubison $f 44$ versus $f 60$ plot, the higher $f 44$ and lower $f 60$ values corresponding to aged biomass burning aerosols.

The AMS biomass burning marker showed a strong variability of aerosol properties well correlated with Lidar mean layers altitude for the second part of the measurements period. During the aging process the biomass burning aerosols 
Ängström exponent decreased from 2 to 1 , while the $f 60$ ranged between 0.009 and 0.007 .

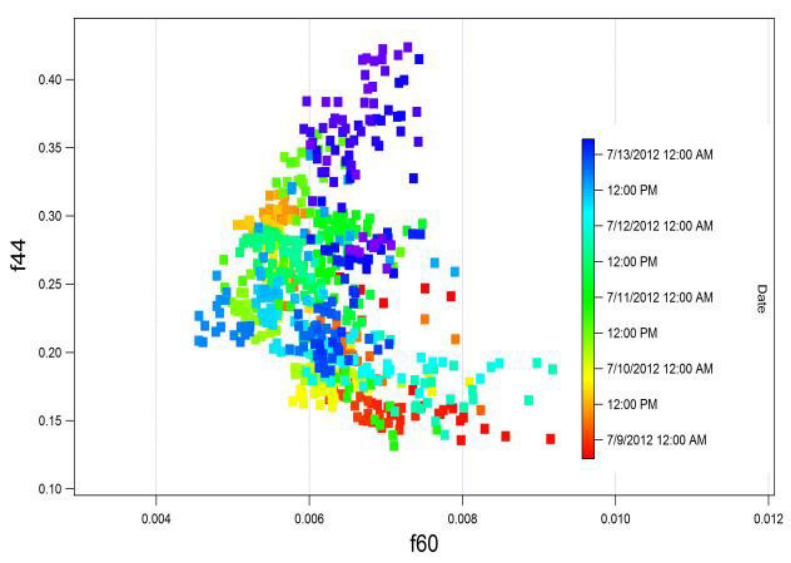

Figure 4 f44 versus f60 for biomass burning aerosols

\section{CONCLUSIONS}

The concentration variations of few specific organic ions have been used to identify biomass burning aerosols and to evidence their evolution. Significant chemical markers of biomass burninglike particles have been noticed for around $40 \%$ of the measurements. Also the Ängström backscatter related coefficient and linear particle depolarization ratio values from lidar continuous measurements pin pointed the presence of low depolarizing and small diameter particles.

The $11^{\text {th }}-13^{\text {th }}$ July period has been characterized by highest $f 60$ values when also Hysplit backtrajectories and MODIS fire indicate biomass burning presence. Correlations of aerosols mean layer height and mass spectrometry biomass burning markers are noticed for half of the measurement period, when conversion from small to higher values of depolarization, from higher to lower layers can be seen. The higher $f 44$ and lower $f 60$ values corresponding to aged biomass burning aerosols are identified for first hours of $12^{\text {th }}$ of July.

\section{ACKNOWLEDGEMENT}

This work was supported by the Programme, Partnerships in S\&T priority domain - PNII, MEN UEFISCDI, project number 309/2014 (MOBBE) and $144 / 2014$ (LIRA), and by the Romanian - Swiss Research Programme, project no IZERZO_ 142146/1. The work of the author F. Toanca was supported by the strategic grant POSDRU/159/1.5/S/137750, "Project
Doctoral and Postdoctoral programs support for increased competitiveness in Exact Sciences research" cofinanced by the European Social Found within the Sectorial Operational Program Human Resources Development 2007-2013.

We acknowledge the use of data products or imagery from the Land, Atmosphere Near real-time Capability for EOS (LANCE) system operated by the NASA/GSFC/Earth Science Data and Information System (ESDIS) with funding provided by NASA/HQ.

\section{REFERENCES}

[1] Müller, D. et al., 2007: Multi-wavelength Raman lidar observations of particle growth during long-range transport of forest-fire smoke in the free troposphere, Geophys. Res. Lett., 34, L05803.

[2] Nemuc, A. et al., 2013: Assessment of aerosol's mass concentrations from measured linear particle depolarization ratio (vertically resolved) and simulations, Atmos. Meas. Tech., 6, 3243-3255.

[3] Amiridis, V. et al., 2009: Optical characteristics of biomass burning aerosols over Southeastern Europe determined from UVRaman lidar measurements, Atmos. Chem. Phys., 9, 2431-2440.

[4] Cubison, M J et al., 2011: Effects of aging on organic aerosol from open biomass burning smoke in aircraft and laboratory studies, Atmos. Chem. Phys. 11, 12049-12064

[5] Alados-Arboledas L. et al., 2011: Optical and microphysical properties of fresh biomass burning aerosol retrieved by Raman lidar, and star-and sunphotometry, Geophys. Res. Lett., 38(1), L01807.

[6] Nicolae, D. et al., 2013: Characterization of fresh and aged biomass burning events using multiwavelength Raman lidar and mass spectrometry, J. Geophys. Res. Atmos., 118, 2956-2965.

[7] Adler G. et al., 2011: Chemical, physical, and optical evolution of biomass burning aerosols: a case study, Atmos. Chem. Phys., 11, 1491-1503.

[8] Wang, Y. et al., 2014: Assimilation of lidar signals: application to aerosol forecasting in the western Mediterranean basin, Atmos. Chem. Phys., 14, 12031-12053.

[9] DeCarlo, P. F. et al., 2006: Field-deployable, high-resolution, time-of-flight aerosol mass spectrometer, Anal. Chem., 78, 8281-8289.

[10] Draxler, R.R. and Rolph, G.D., 2012: HYSPLIT (HYbrid Single-Particle Lagrangian Integrated Trajectory) Model access via NOAA ARL READY Website 